\title{
Analisis Pengaruh Perubahan Beban Terhadap Biaya Bahan Bakar Pembangkitan Pada PLTU Barru
}

\author{
La Ode Musa ${ }^{1 *}$, Musrady Mulyadi ${ }^{2}$, Muh. Fachriyadi Hastira ${ }^{3}$ dan Hasniaty $^{4}$ \\ 1,2,3,4 Jurusan Teknik Mesin, Politeknik Negeri Ujung Pandang, Makassar 90245, Indonesia \\ *laode_musa@poliupg.ac.id
}

\begin{abstract}
The effect of changes in load on the cost of fuel generation at PLTU Barru is analyzed using the economic dispatch method to determine the characteristics of input-output and incremental fuel costs. Based on the results of the analysis, it is known that the effect of changes in load on the cost of fuel generation at PLTU Barru tends to be directly proportional, where the higher the load generated, the higher the costs incurred. As in June, to produce $33.85 \mathrm{MW}$ of power the total cost is Rp. 457,687,187.47/hour required. Likewise, if the power at an average load of $33.85 \mathrm{MW}$ increases by $1 \mathrm{MWh}$ it will result in an increase in costs of Rp. 13,306,061.24/MWh, but in certain circumstances such as in November with a power of $29.83 \mathrm{MW}$ it will produce the total cost is quite low at Rp. 337,356,512,63/hour. This situation is caused by fuel consumption in November only amounted to $3029.61 \mathrm{~T} / \mathrm{h}$.
\end{abstract}

Keywords: input-output characteristics; incremental fuel cost; fuel cost

\begin{abstract}
Abstrak: Pengaruh perubahan beban terhadap biaya bahan bakar pembangkitan pada PLTU Barru dianalisa dengan menggunakan metode economic dispatch untuk mengetahui karakteristik input-output serta incremental fuel cost. Berdasarkan hasil analisa diketahui bahwa pengaruh perubahan beban terhadap biaya bahan bakar pembangkitan pada PLTU Barru cenderung berbanding lurus, dimana semakin tinggi beban yang dihasilkan maka semakin tinggi pula biaya yang dikeluarkan. Seperti pada bulan Juni, untuk menghasilkan daya 33,85 MW total biaya sebesar Rp. 457.687.187,47/jam diperlukan. Demikian juga bila daya pada beban rata-rata sebesar 33,85 MW meningkat sebesar $1 \mathrm{MWh}$ maka akan menghasilkan kenaikan biaya sebesar Rp.13.306.061,24/MWh, namun pada keadaaan tertentu seperti pada bulan November dengan daya yaitu 29,83 MW menghasilkan total biaya yang cukup rendah sebesar Rp.337.356.512,63/jam. Keadaan ini disebabkan karena konsumsi bahan bakar di bulan November hanya sebesar 3029,61 T/h.
\end{abstract}

Kata kunci: karakteristik input-output; incremental fuel cost; biaya bahan bakar

\section{PENDAHULUAN}

Energi listrik yang dibangkitkan tidak dapat ditampung dalam skala yang besar, sehingga energi yang dimaksud harus tersedia pada saat diperlukan. Daya yang terbangkitkan harus berbanding lurus dengan daya yang dikonsumsi oleh konsumen. Sehingga timbul peersoalan bagaimana suatu sistem tenaga listrik harus terus dioperasikan agar dapat memenuhi permintaan daya yang berfluktuasi setiap saat, dengan kualitas yang baik dan harga yang murah. Menurut [1], "Faktor - faktor yang mempengaruhi pengiriman daya nyata yang optimal pada pembangkit adalah beroperasinya generator yang efisien, biaya bahan bakar, dan rugi-rugi daya pada saluran transmisi."

Fluktuasi kebutuhan energi listrik disisi beban akan menimbulkan fluktuasi perubahan biaya bahan bakar [2], "Output pembangkit yang dihasilkan selalu diupayakan agar sama dengan besar kebutuhan di sisi beban, karena perubahan kebutuhan energi listrik di sisi beban akan menimbulkan fluktuasi biaya bahan bakar." Sistem tenaga listrik yang besar seperti Pembangkit Listrik Tenaga Uap (PLTU) akan menghadapi permasalahan dalam hal biaya bahan bakar untuk pengoperasiannya.

Biaya bahan bakar sebuah pembangkitan sangat mempengaruhi daya yang dihasilkan, yang kemudian akan mempegaruhi beban. Hal ini dipertegas oleh [3], "Biaya bahan bakar sebuah unit pembangkit merupakan fungsi beban suatu pembangkit." Perubahan permintaan beban yang terjadi akan menyebabkan fluktuasi pada biaya bahan bakar sehingga menyebabkan biaya bahan bakar tidak 
ekonomis. Oleh karena itu, perlu dilakukan suatu analisa tentang pengaruh perubahan beban tersebut terhadap biaya operasi khususnya pada biaya bahan bakar yang dikeluarkan.

\section{A. Operasi Ekonomis Sistem Tenaga}

Menurut [4], Operasi ekonomis ialah proses pembagian beban total kepada masing-masing unit pembangkit, seluruh unit pembangkit dikontrol terus menerus dalam interval waktu tertentu sehingga dicapai pengoperasian yang optimal, dengan demikian pembangkit tenaga listrik dapat dilakukan dengan cara paling ekonomis. Menurut [1], ada beberapa faktor yang mempengaruhi kurangnya biaya pada suatu sistem pembangkit tenaga listrik adalah efisiensi dari generator, rugi-rugi pada jaringan transmisi, dan biaya bahan bakar. Salah satu yang menyebabkan suatu pembangkit tidak ekonomis adalah biaya bahan bakar yang cukup besar.

Output pembangkit yang dihasilkan selalu diupayakan sama dengan besar kebutuhan disisi beban atau konsumen. Naik turunnya kebutuhan energi lstrik disisi beban akan menimbulkan naik turunnya biaya bahan bakar, hubungan keduanya dikatakan sebagai input output suatu pembangkit tenaga listrik, hal ini sama dengan yang dikemukan oleh [2], "Output pembangkit yang dihasilkan selalu diupayakan agar sama dengan besar kebutuhan di sisi beban, karena perubahan kebutuhan energi listrik di sisi beban akan menimbulkan fluktuasi biaya bahan bakar. Korelasi antara keduanya dinyatakan dalam karakteristik Input-Output suatu pembangkit tenaga listrik". Selain dari pada itu, pengoperasian sistem yang efisien sangat penting hingga dapat menjamin hubungan yang setara antara biaya yang dikeluarkan oleh perusahaan listrik untuk memproduksi satu kilowatt jam dengan biaya yang harus dibayar oleh pelanggan.

Menurut [5], dapat dilihat bahwa setiap peningkatan dalam permintaan beban membawa kenaikan yang sama dalam biaya bahan bakar sistem; biaya yang akan diteruskan kepada pelanggan karena biaya bahan bakar membawa persentase tertinggi dari biaya operasi pembangkit listrik. Oleh karena itu, ini menunjukkan bahwa hubungan antara harga bahan bakar dan permintaan Beban kira-kira linear.

\section{B. Pembangkit Listrik Tenaga Uap Barru (PLTU Barru)}

PLTU Barru yang dibangun menggunakan bahan bakar batubara berkalori rendah (LHV: 3700 $4700 \mathrm{Kcal} / \mathrm{kg}$ ) memerlukan batubara pertahun sebesar 564.000 ton dan diangkut menggunakan barge/tongkang menuju ke PLTU melalui jetty sebagai sarana pelabuhan khusus bongkar muat batubara dan energi listrik yang dihasilkan PLTU disalurkan melalui Saluran Udara Tegangan Tinggi (SUTT) $150 \mathrm{kV}$ ke Gardu Induk (GI) $150 \mathrm{kV}$ Parepare sepanjang $\pm 40 \mathrm{Km}$ dan Gardu Induk $150 \mathrm{kV}$ Pangkep sepanjang $\pm 50 \mathrm{Km}$.

Spesifikasi Generator PLTU Barru (Operation Manual PLTU Sulawasi Selatan 2 x 50MW Coalfired Steam Power Plant Turbin) :

$\begin{array}{ll}\text { Manufacture } & : \text { Nanjing Turbine dan Electric Machinery Group } \\ \text { Type } & : \text { QFW-60-2C } \\ \text { Rated Power } & : 50 \mathrm{MW} \\ \text { Rated Output } & : 70.6 \mathrm{MVA} \\ \text { Rated Voltage } & : 10.5 \mathrm{kV} \\ \text { Rated Current } & : 3882 \mathrm{~A} \\ \text { Excitation Current } & : 740 \mathrm{~A} \\ \text { Frequency } & : 50 \mathrm{~Hz} \\ \text { Rated Speed } & : 3000 \mathrm{rpm} \\ \text { Power Factor } & : 0.85 \\ \text { Insulation Class } & : \mathrm{F} \\ \text { Connection } & : Y \\ \text { Weight } & : 110 \mathrm{t}\end{array}$


90 La Ode Musa, Musrady Mulyadi, Muh. Fachriyadi Hastira, Hasniaty. Analisis Pengaruh Perubahan Beban Terhadap Biaya Bahan Bakar Pembangkitan Pada PLTU Barru

\section{METODE PENELITIAN}

Karakteristik pembangkit listrik sangatlah penting guna menekan biaya bahan bakar pada suatu pembangkit. Berdasarkan karakeristik pembangkit listrik maka pengaturan output pembangkit dapat diatur dengan baik sehingga biaya bahan bakar energi dapat diminimalisir, dan dapat dibuat model matematis untuk proses optimasi agar dihasilkan biaya pembangkitan yang ekonomis.

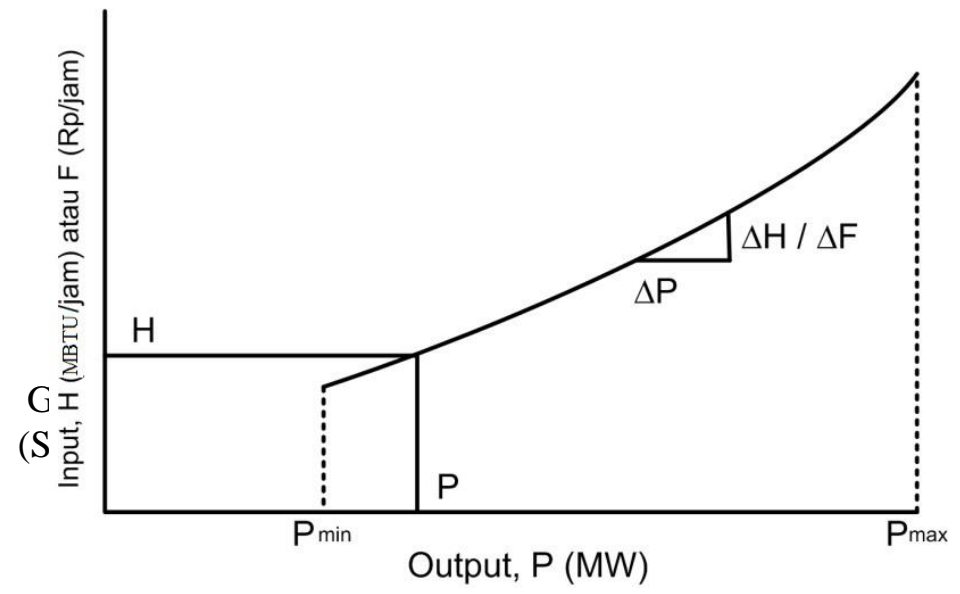

Gambar 1. Kurva Krakteristik Input-Output Unit Termal

Gambar 1 merupakan karakteristik input-output dari unit pembangkit termal yang ideal digambarkan sebagai kurva non-linear yang berkelanjutan. Menurut [2], data karakteristik input-output dapat diperoleh dari perhitungan desain atau dari pengukuran atau bahkan berdasarkan data dari pabriknya. Input dari pembangkit ditunjukkan pada sumbu tegak yaitu energi panas yang dibutuhkan dalam bentuk MBTU/h atau biaya total perjam $(\mathrm{Rp} / \mathrm{h})$.

Output dari pembangkit ditunjukkan pada sumbu mendatar yaitu daya listrik, yang memiliki batas-batas kritis operasi yaitu daya maksimum dan minimum dari pembangkit. Kurva ini didapat dari hasil tes panas pembangkit uap atau dari hasil yang didapat dari pencarian laju panas pembangkit. Analisis ini dapat menggunakan metode regresi kuadrat terkecil untuk mencari konstanta input-output $\left(\alpha_{n}, \beta_{n}, \gamma_{n}\right)$ yang digunakan menentukan persamaan input-output pada pembangkit uap [5]:

$$
y=a x^{2}+b x+c
$$

Dimana:

$$
\begin{aligned}
& a=\frac{\left\{\left[\sum\left(x^{2} y\right) \sum\left(x^{2}\right)-\sum(x y) \sum\left(x^{3}\right)\right]\right\}}{\left[\sum\left(x^{2}\right) \sum\left(x^{4}\right)-\left[\sum\left(x^{3}\right)\right]^{2}\right]} \\
& b=\frac{\left\{\left[\sum(x y) \sum\left(x^{2} y\right)-\sum(x y) \sum\left(x^{3}\right)\right]\right\}}{\left[\sum\left(x^{2}\right) \sum\left(x^{4}\right)-\left[\sum\left(x^{3}\right)\right]^{2}\right]} \\
& c=\left[\frac{\sum\left(y_{i}\right)}{n}\right]-\left\{b\left[\frac{\sum\left(x_{i}\right)}{n}\right]\right\}-\left\{a\left[\frac{\sum\left(x_{i}^{2}\right)}{n}\right]\right\}
\end{aligned}
$$

Selain dari pada itu, metode lain yang dapat digunakan adalah pendekatan fungsi polinomial orde dua yaitu:

$$
\mathrm{H}_{\mathrm{n}}=\alpha_{\mathrm{n}}+\beta_{\mathrm{n}} \mathrm{P}_{\mathrm{n}}+\gamma_{\mathrm{n}} \mathrm{P}_{\mathrm{n}}{ }^{2}
$$

Dimana: 
$\mathrm{H}_{\mathrm{n}} \quad$ = Input bahan bakar pembangkit termal unit ke-n (Ton/h)

$\mathrm{P}_{\mathrm{n}} \quad=$ Output pembangkit termal unit ke-n (MW)

$\alpha_{n}, \beta_{n}, \gamma_{n}=$ Konstanta Input-Output pembangkit termal unit ke-n

Penentuan konstanta $\alpha_{n}, \beta_{n}, \gamma_{n}$ membutuhkan data yang berhubungan dengan input bahan bakar $\mathrm{H}_{\mathrm{n}}(\mathrm{T} / \mathrm{h})$ dan output pembangkit $\mathrm{P}_{\mathrm{n}}(\mathrm{MW})$ yang dapat dijabarkan sebagai berikut :

$$
\mathrm{S}=\Sigma\left(\alpha_{\mathrm{n}}+\beta_{\mathrm{n}} \mathrm{P}_{\mathrm{n}}{ }^{2}+\gamma_{\mathrm{n}} \mathrm{H}_{\mathrm{n}}{ }^{2}-\mathrm{H}_{\mathrm{n}}\right)^{2}
$$

Dimana persyaratan yang harus dipenuhi adalah sebagai berikut:

$$
\begin{aligned}
& \frac{\partial \mathrm{S}}{\partial \alpha}=\Sigma 2\left(\alpha_{\mathrm{n}}+\beta_{\mathrm{n}} \mathrm{P}_{\mathrm{n}}+\gamma_{\mathrm{n}} \mathrm{P}_{\mathrm{n}}{ }^{2}-\mathrm{H}_{\mathrm{n}}\right)=0 \ldots \ldots . \\
& \frac{\partial \mathrm{S}}{\partial \beta}=\Sigma 2 \mathrm{P}_{\mathrm{n}}\left(\alpha_{\mathrm{n}}+\beta_{\mathrm{n}} \mathrm{P}_{\mathrm{n}}+\gamma_{\mathrm{n}} \mathrm{P}_{\mathrm{n}}^{2}-\mathrm{H}_{\mathrm{n}}\right)=0 . \\
& \frac{\partial \mathrm{S}}{\partial \beta}=\Sigma 2 \mathrm{P}_{\mathrm{n}}{ }^{2}\left(\alpha_{\mathrm{n}}+\beta_{\mathrm{n}} \mathrm{P}_{\mathrm{n}}+\gamma_{\mathrm{n}} \mathrm{P}_{\mathrm{n}}{ }^{2}-\mathrm{H}_{\mathrm{n}}\right)=0
\end{aligned}
$$

Sehingga :

$$
(\mathrm{N}) \alpha_{\mathrm{n}}+\left(\Sigma \mathrm{P}_{\mathrm{n}}\right) \beta_{\mathrm{n}}+\left(\Sigma \mathrm{P}_{\mathrm{n}}^{2}\right) \gamma_{\mathrm{n}}=\Sigma \mathrm{H}_{\mathrm{n}}
$$

$$
\left(\Sigma \mathrm{P}_{\mathrm{n}}\right) \alpha_{\mathrm{n}}+\left(\Sigma \mathrm{P}_{\mathrm{n}}^{2}\right) \beta_{\mathrm{n}}+\left(\Sigma \mathrm{P}_{\mathrm{n}}^{3}\right) \gamma_{\mathrm{n}}=\Sigma \mathrm{H}_{\mathrm{n}}
$$

$$
\left(\Sigma \mathrm{P}_{\mathrm{n}}{ }^{2}\right) \alpha_{\mathrm{n}}+\left(\Sigma \mathrm{P}_{\mathrm{n}}^{3}\right) \beta_{\mathrm{n}}+\left(\Sigma \mathrm{P}_{\mathrm{n}}^{4}\right) \gamma_{\mathrm{n}}=\Sigma \mathrm{H}_{\mathrm{n}} \mathrm{P}_{\mathrm{n}}{ }^{2}
$$

Maka akan membentuk suatu Sistem Persamaan Linear Tiga Variabel dengan orde 3 pada persamaan (6), (7), (8), bila disusun sebagai berikut:

$$
\left[\begin{array}{ccc}
\mathrm{N} & \Sigma \mathrm{P}_{\mathrm{n}} & \Sigma \mathrm{P}_{\mathrm{n}}{ }^{2} \\
\Sigma \mathrm{P}_{\mathrm{n}} & \Sigma \mathrm{P}_{\mathrm{n}}{ }^{2} & \Sigma \mathrm{P}_{\mathrm{n}}{ }^{3} \\
\Sigma \mathrm{P}_{\mathrm{n}}{ }^{2} & \Sigma \mathrm{P}_{\mathrm{n}}{ }^{3} & \Sigma \mathrm{P}_{\mathrm{n}}{ }^{4}
\end{array}\right]\left[\begin{array}{c}
\alpha_{\mathrm{n}} \\
\beta_{\mathrm{n}} \\
\gamma_{\mathrm{n}}
\end{array}\right]=\left[\begin{array}{c}
\Sigma \mathrm{H}_{\mathrm{n}} \\
\Sigma \mathrm{H}_{\mathrm{n}} \mathrm{P}_{\mathrm{n}} \\
\Sigma \mathrm{H}_{\mathrm{n}} \mathrm{P}_{\mathrm{n}}{ }^{2}
\end{array}\right]
$$

Solusi pada persamaan (9) dapat diselesaikan dengan cara :

$$
\begin{aligned}
& \alpha_{\mathrm{n}}= \frac{\left[\begin{array}{ccc}
\Sigma \mathrm{H}_{\mathrm{n}} & \Sigma \mathrm{P}_{\mathrm{n}} & \Sigma \mathrm{P}_{\mathrm{n}}{ }^{2} \\
\Sigma \mathrm{H}_{\mathrm{n}} \mathrm{P}_{\mathrm{n}} & \Sigma \mathrm{P}_{\mathrm{n}}{ }^{2} & \Sigma \mathrm{P}_{\mathrm{n}}{ }^{3} \\
\Sigma \mathrm{H}_{\mathrm{n}} \mathrm{P}_{\mathrm{n}}{ }^{2} & \Sigma \mathrm{P}_{\mathrm{n}}{ }^{3} & \Sigma \mathrm{P}_{\mathrm{n}}{ }^{4}
\end{array}\right]}{\left[\begin{array}{ccc}
\mathrm{N} & \Sigma \mathrm{P}_{\mathrm{n}} & \Sigma \mathrm{P}_{\mathrm{n}}{ }^{2} \\
\Sigma \mathrm{P}_{\mathrm{n}} & \Sigma \mathrm{P}_{\mathrm{n}}{ }^{2} & \Sigma \mathrm{P}_{\mathrm{n}}{ }^{3} \\
\Sigma \mathrm{P}_{\mathrm{n}}{ }^{2} & \Sigma \mathrm{P}_{\mathrm{n}}{ }^{3} & \Sigma \mathrm{P}_{\mathrm{n}}{ }^{4}
\end{array}\right]} \\
& \beta_{\mathrm{n}}=\frac{\left[\begin{array}{ccc}
\mathrm{N} & \Sigma \mathrm{H}_{\mathrm{n}} & \Sigma \mathrm{P}_{\mathrm{n}}{ }^{2} \\
\Sigma \mathrm{P}_{\mathrm{n}} & \Sigma \mathrm{H}_{\mathrm{n}} \mathrm{P}_{\mathrm{n}} & \Sigma \mathrm{P}_{\mathrm{n}}{ }^{3} \\
\Sigma \mathrm{P}_{\mathrm{n}}{ }^{2} & \Sigma \mathrm{H}_{\mathrm{n}} \mathrm{P}_{\mathrm{n}}{ }^{2} & \Sigma \mathrm{P}_{\mathrm{n}}{ }^{4}
\end{array}\right]}{\left[\begin{array}{ccc}
\mathrm{N} & \Sigma \mathrm{P}_{\mathrm{n}} & \Sigma \mathrm{P}_{\mathrm{n}}{ }^{2} \\
\Sigma \mathrm{P}_{\mathrm{n}} & \Sigma \mathrm{P}_{\mathrm{n}}{ }^{2} & \Sigma \mathrm{P}_{\mathrm{n}}{ }^{3} \\
\Sigma \mathrm{P}_{\mathrm{n}}{ }^{2} & \Sigma \mathrm{P}_{\mathrm{n}}{ }^{3} & \Sigma \mathrm{P}_{\mathrm{n}}{ }^{4}
\end{array}\right]}
\end{aligned}
$$


92 La Ode Musa, Musrady Mulyadi, Muh. Fachriyadi Hastira, Hasniaty. Analisis Pengaruh Perubahan Beban Terhadap Biaya Bahan Bakar Pembangkitan Pada PLTU Barru

$$
\gamma_{\mathrm{n}}=\frac{\left[\begin{array}{ccc}
\mathrm{N} & \Sigma \mathrm{P}_{\mathrm{n}} & \Sigma \mathrm{H}_{\mathrm{n}} \\
\Sigma \mathrm{P}_{\mathrm{n}} & \Sigma \mathrm{P}_{\mathrm{n}}{ }^{2} & \Sigma \mathrm{H}_{\mathrm{n}} \mathrm{P}_{\mathrm{n}} \\
\Sigma \mathrm{P}_{\mathrm{n}}{ }^{2} & \Sigma \mathrm{P}_{\mathrm{n}}{ }^{3} & \Sigma \mathrm{H}_{\mathrm{n}} \mathrm{P}_{\mathrm{n}}{ }^{2}
\end{array}\right]}{\left[\begin{array}{ccc}
\mathrm{N} & \Sigma \mathrm{P}_{\mathrm{n}} & \Sigma \mathrm{P}_{\mathrm{n}}{ }^{2} \\
\Sigma \mathrm{P}_{\mathrm{n}} & \Sigma \mathrm{P}_{\mathrm{n}}{ }^{2} & \Sigma \mathrm{P}_{\mathrm{n}}{ }^{3} \\
\Sigma \mathrm{P}_{\mathrm{n}}{ }^{2} & \Sigma \mathrm{P}_{\mathrm{n}}{ }^{3} & \Sigma \mathrm{P}_{\mathrm{n}}{ }^{4}
\end{array}\right]}
$$

Sehingga akan diperoleh persamaan biaya bahan bakar sebagai berikut: dimana:

$$
F_{n}=\left(\alpha_{n}+\beta_{n} P_{n}+\gamma_{n} P_{n}^{2}\right) \times F_{t}
$$

$$
\begin{array}{ll}
\mathrm{F}_{\mathrm{t}} & =\text { Harga Batubara }(\mathrm{Rp} / \mathrm{Ton}) \\
\mathrm{F}_{\mathrm{n}} & =\text { biaya bahan bakar }(\mathrm{Rp} / \mathrm{h}) \\
\mathrm{P}_{\mathrm{n}} & =\text { Output daya pembangkit unit ke-n }(\mathrm{MW}) \\
\alpha_{\mathrm{n}}, \beta_{\mathrm{n}}, \gamma_{\mathrm{n}} & =\text { Konstanta ke- } \mathrm{n}
\end{array}
$$

Hasil dari persamaan ini digunakan untuk membuat kurva karakteristik input-output.

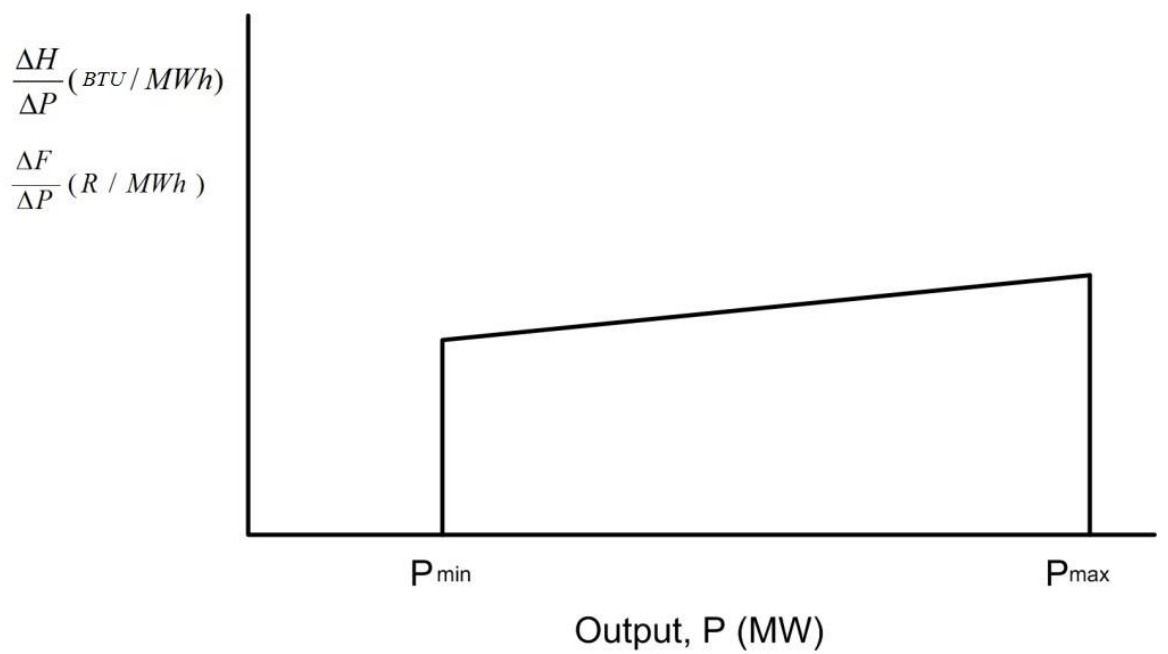

Gambar 2. Krakteristik Kenaikan panas/Biaya Unit

Karakteristik kenaikan panas/biaya unit atau biasa disebut karakteristik incremental cost dari unit pembangkit termal ditunjukkan pada Gambar 2. Karakteristik ini adalah kemiringan/slope dari karakteristik Input-Output $(\Delta \mathrm{H} / \Delta \mathrm{P}$ atau $\Delta \mathrm{F} / \Delta \mathrm{P})$ atau turunan pertama dari karakteristik input- output.

Karakteristik ini menunjukan bahwa nilai BTU per $\mathrm{MWh}$ atau $\mathrm{Rp} / \mathrm{MWh}$ terhadap daya keluaran dalam satuan MW. Karakteristik ini digunakan untuk perhitungan pembebanan ekonomis dari unit pembangkit. Jika persamaan Input-Output unit pembangkit dinyatakan dalam pendekatan dengan menggunakan persaman kuadrat, maka karakteristik incremental fuel cost akan mempunyai bentuk garis lurus. Secara umum untuk mencari persamaan incremental fuel cost (Rp/MWh) didefinisikan dengan persamaan:

$$
\frac{\partial F_{n}}{\partial P_{n}}=\beta_{n}+2 \gamma_{n} P_{n}
$$


Dimana:

$$
\begin{aligned}
& \frac{\partial \mathrm{F}_{\mathrm{n}}}{\partial \mathrm{P}_{\mathrm{n}}}=\text { Kenaikan biaya bahan bakar }(\mathrm{Rp} / \mathrm{MWh}) \\
& \mathrm{P}_{\mathrm{n}} \quad=\text { Output daya pembangkit unit ke-n (MW) } \\
& \beta_{\mathrm{n}}, \gamma_{\mathrm{n}}=\text { Konstanta ke-n }
\end{aligned}
$$

Kurva incremental fuel cost didapatkan dengan menggunakan parameter-parameter pada persamaan 13 yang disubtitusi ke persamaan 14. Analisis dinyatakan dalam flowchart pada gambar 3.

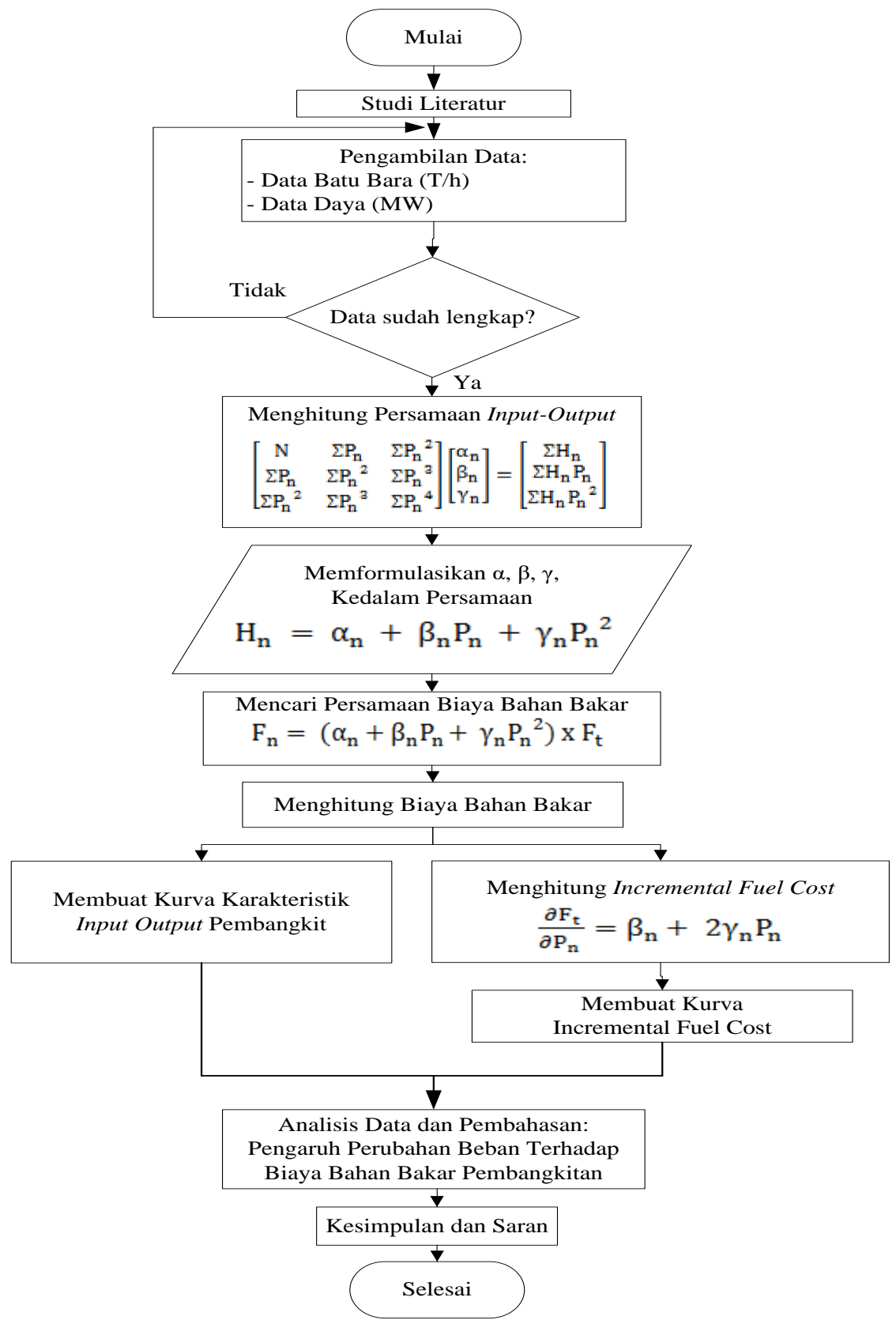

Gambar 3. Flow Chart Penelitian dan Analisa Data 
94 La Ode Musa, Musrady Mulyadi, Muh. Fachriyadi Hastira, Hasniaty. Analisis Pengaruh Perubahan Beban Terhadap Biaya Bahan Bakar Pembangkitan Pada PLTU Barru

\section{HASIL DAN PEMBAHASAN}

Analisis data dilakukan secara manual menggunakan rumus konvensional serta program MATLAB dan MS. Excel. Data yang dipakai sebagai sampel pada penelitian ini adalah data Input-Output pada PLTU Barru unit 1 pada bulan Juni 2017 seperti pada tabel berikut:

Tabel 1. Data Input-Output Bulan Juni 2017

\begin{tabular}{|c|c|c|c|c|c|}
\hline \multicolumn{6}{|c|}{ Juni } \\
\hline \multirow[b]{2}{*}{ Tanggal } & \multicolumn{2}{|c|}{ Input } & \multicolumn{2}{|c|}{ Output } & \multirow[b]{2}{*}{$\begin{array}{c}\text { Pemakaian } \\
\text { Sendiri (MW) }\end{array}$} \\
\hline & $\begin{array}{c}\text { Pemakaian Batu } \\
\text { Bara }(\mathrm{T} / \mathrm{h})\end{array}$ & $\begin{array}{c}\text { Nilai Kalori } \\
\text { (kkal) }\end{array}$ & $\begin{array}{l}\text { Gross } \\
\text { (MW) }\end{array}$ & $\begin{array}{l}\text { Netto } \\
\text { (MW) }\end{array}$ & \\
\hline 1 & 703,88 & 4526,00 & 36,91 & 33,04 & 4,50 \\
\hline 2 & 643,15 & 3987,00 & 33,44 & 28,19 & 3,95 \\
\hline 3 & 669,64 & 4009,00 & 34,96 & 30,32 & 4,38 \\
\hline 4 & 698,68 & 4377,00 & 36,96 & 32,24 & 4,37 \\
\hline 5 & 657,89 & 4908,00 & 34,70 & 30,10 & 4,38 \\
\hline 6 & 737,69 & 4308,00 & 38,48 & 33,30 & 4,50 \\
\hline 7 & 808,15 & 4163,00 & 41,74 & 37,33 & 4,37 \\
\hline 8 & 773,27 & 4067,00 & 39,43 & 34,78 & 4,38 \\
\hline 9 & 814,82 & 4105,00 & 42,11 & 37,31 & 4,40 \\
\hline 10 & 810,96 & 4128,00 & 42,05 & 36,91 & 4,40 \\
\hline 11 & 805,29 & 4091,00 & 41,00 & 36,38 & 4,39 \\
\hline 12 & 818,24 & 3977,00 & 41,53 & 36,90 & 4,42 \\
\hline 13 & 825,84 & 4323,00 & 42,16 & 36,85 & 4,39 \\
\hline 14 & 806,31 & 4439,00 & 41,27 & 36,13 & 4,38 \\
\hline 15 & 805,27 & 4146,00 & 41,16 & 36,46 & 4,42 \\
\hline 16 & 816,28 & 4076,00 & 41,26 & 36,52 & 4,38 \\
\hline 17 & 823,49 & 3983,00 & 41,11 & 36,32 & 4,50 \\
\hline 18 & 824,74 & 4542,00 & 41,16 & 36,42 & 4,50 \\
\hline 19 & 821,59 & 3690,00 & 41,47 & 36,37 & 4,54 \\
\hline 20 & 832,10 & 4309,00 & 41,95 & 36,25 & 4,95 \\
\hline 21 & 802,52 & 4168,00 & 40,74 & 36,12 & 4,81 \\
\hline 22 & 821,33 & 4203,48 & 41,42 & 36,13 & 4,58 \\
\hline 23 & 809,74 & 4053,00 & 41,32 & 36,28 & 4,46 \\
\hline 24 & 670,44 & 4102,00 & 34,44 & 29,21 & 4,39 \\
\hline 25 & 615,15 & 4153,00 & 30,71 & 25,89 & 4,38 \\
\hline 26 & 571,74 & 4340,00 & 30,19 & 25,07 & 4,53 \\
\hline 27 & 676,75 & 4339,89 & 34,02 & 29,16 & 4,70 \\
\hline 28 & 751,99 & 3934,00 & 38,69 & 33,85 & 4,93 \\
\hline 29 & 750,35 & 3913,00 & 38,85 & 33,51 & 4,93 \\
\hline 30 & 727,29 & 3990,00 & 37,54 & 32,08 & 4,87 \\
\hline Rata - Rata & 756,49 & 4178,35 & 38,76 & 33,85 & 4,50 \\
\hline Total & 22694,58 & 125350,37 & 1162,77 & $\mathbf{1 0 1 5 , 4 3}$ & 135,05 \\
\hline
\end{tabular}

Berdasarkan analisis yang dilakukan didapatkan 2 buah kurva yaitu karakteristik input-output dan kurva incremetal fuel cost. 


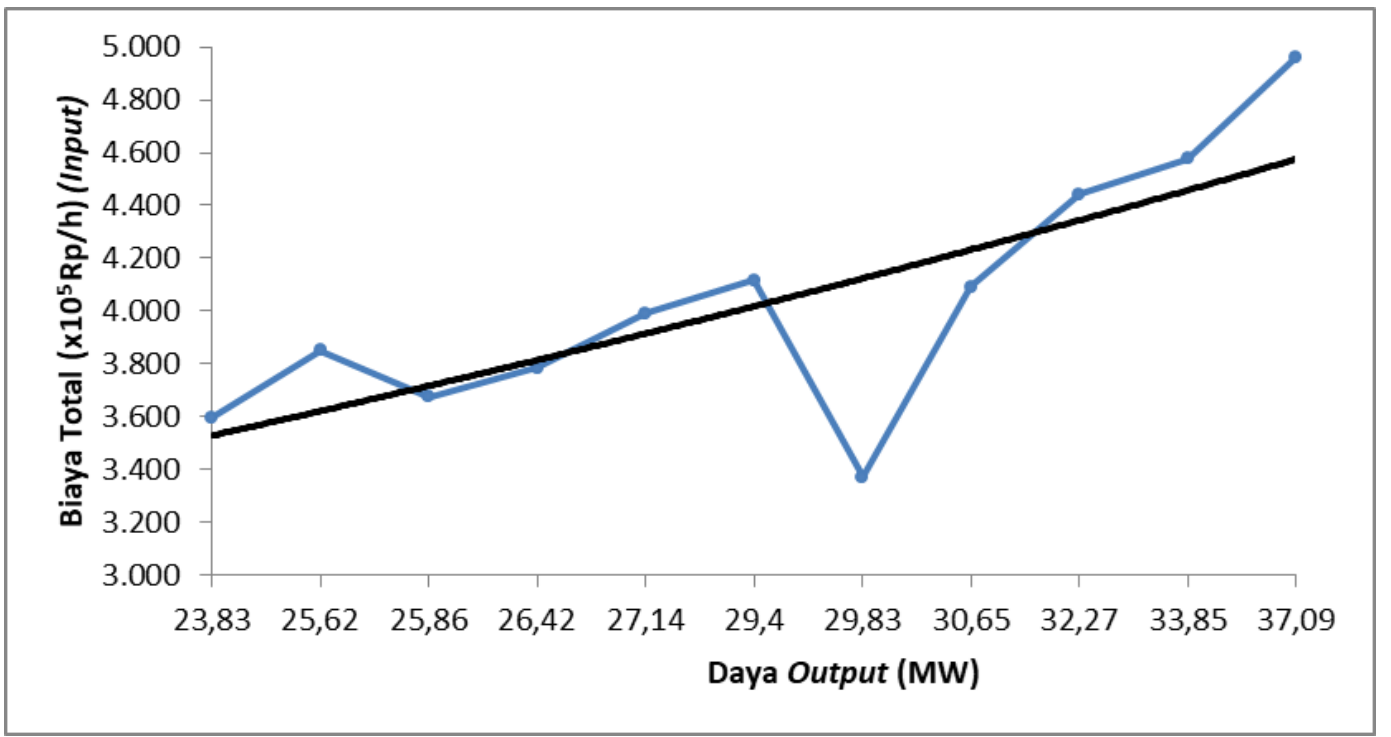

Gambar 4. Kurva Karakteristik Input-Output (Hubungan Antara Biaya Total terhadap Daya Output) Pembangkit PLTU Barru Unit 1 pada Tahun 2017 (Berurut Berdasarkan Daya Terendah Ke Tertinggi)

Berdasarkan kurva karakteristik input-output ideal pada Gambar 1, dapat dilihat bahwa semakin tinggi nilai daya (MW) yang dihasilkan maka semakin tinggi pula total biaya perjam $(\mathrm{Rp} / \mathrm{h})$ yang dikeluarkan. Bila dibandingkan dengan Gambar 4, hubungan antara total biaya perjam $(\mathrm{Rp} / \mathrm{h})$ terhadap daya output (MW), dimana daya output tertinggi 37,09 MW memerlukan total biaya sebesar Rp. 496.280.937,70/jam sedangkan daya terendah 23,83 MW memerlukan total biaya sebesar Rp. 359.594.955,17/jam, namun pada keadaaan tertentu seperti pada bulan November didapatkan daya yang tinggi yaitu 29,83 MW dengan total biaya yang rendah yaitu Rp. 337.356.512,63/jam. Keadaan ini disebabkan karena konsumsi bahan bakar di bulan November hanya sebesar 3029,61 T/h.

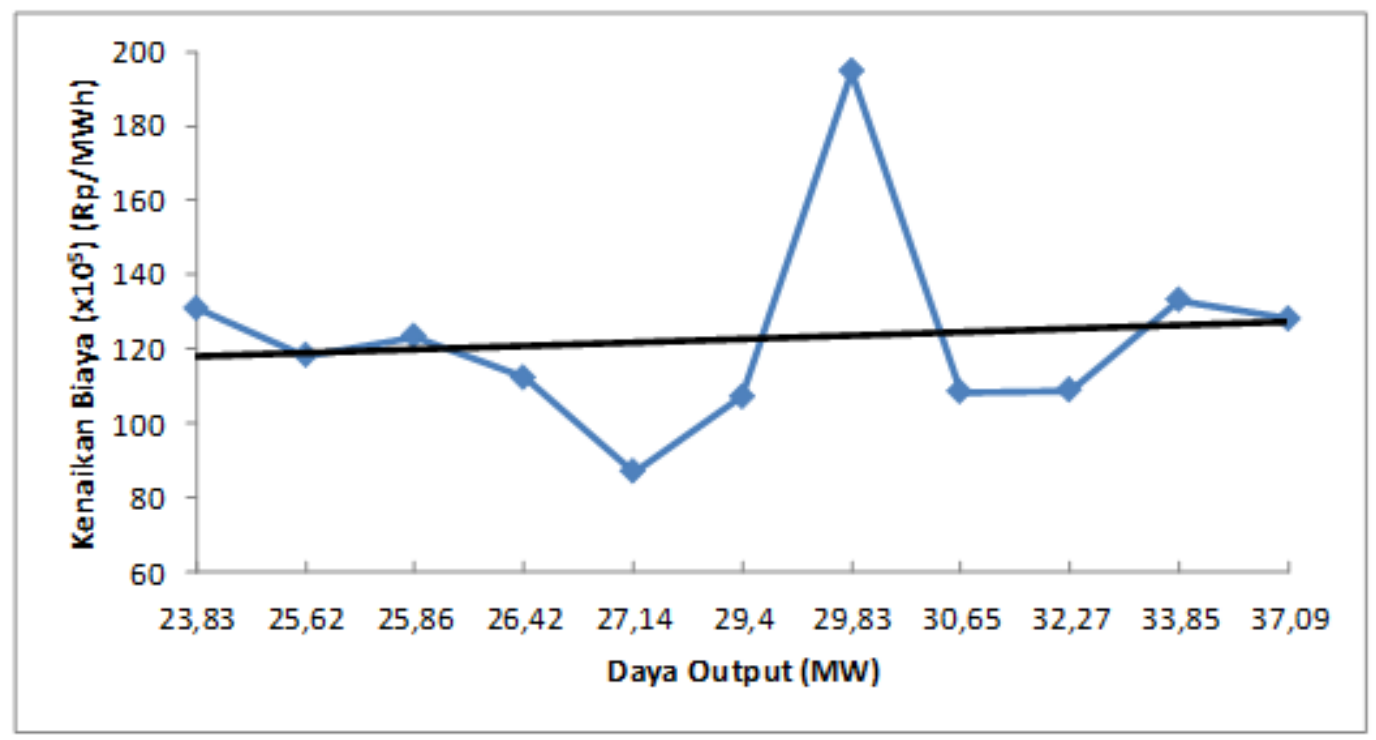

Gambar 5. Kurva Incremental Fuel Cost (Hubungan antara Kenaikan Biaya terhadap Daya Output) PLTU Barru Unit 1 pada Tahun 2017 (Berurut Berdasarkan Daya Terendah Ke Tertinggi) 
Berdasarkan gambar diatas yaitu hubungan antara kenaikan biaya perjam (Rp/MWh) terhadap daya output (MW). Daya output tertinggi 37,09 MW menghasilkan kenaikan biaya sebesar Rp.12.811.883,94/MWh sedangkan daya terendah 23,83 MW menghasilkan kenaikan biaya sebesar sebesar Rp.13.090.576,34/MWh jika dinaikkan $1 \mathrm{MWh}$.

Berdasarkan gambar diatas dapat dilihat bahwa bulan Januari mengalami kenaikan biaya sebesar Rp.13.090.576,34/MWh dengan daya rata-rata 23,83, kemudian pada bulan Februari dan Maret terjadi penurunan kenaikan biaya berturut-turut sebesar Rp.11.816.590,24/MWh dan Rp.10.830.488,05/MWh dengan daya rata-rata yang tinggi dibandingkan dengan bulan Januari yaitu 25,62 MW dan 30,65 MW, keadaan ini disebabkan karena rentang waktu unit beroperasi pada bulan Januari lebih sedikit dibandingkan dengan bulan Februari dan Maret. Selanjutnya pada bulan April September kenaikan biaya berfluktuatif yang disebabkan karena rentang waktu unit beroperasi juga berfluktuatif, namun pada bulan Oktober - November kenaikan biaya mengalami kenaikan yang drastis yang disebabkan oleh rentang waktu operasi yang menurun drastis pada bulan November. Sehingga dapat dikatakan bahwa semakin sedikit rentang waktu unit beroperasi maka kenaikan biaya yang didapatkan semakin besar pada daya yang sama.

\section{KESIMPULAN}

Berdasarkan hasil analisa yang diperoleh dapat disimpulkan bahwa pengaruh perubahan beban terhadap biaya bahan bakar pembangkitan pada PLTU Barru cenderung berbanding lurus, dimana semakin tinggi beban yang dihasilkan maka semakin tinggi pula biaya yang dikeluarkan, seperti data pada bulan Juni, untuk menghasilkan daya 33,85 MW total biaya sebesar Rp. 457.687.187,47/jam diperlukan. Bila daya meningkat sebesar 1 MW maka akan menghasilkan kenaikan biaya sebesar Rp. 13.306.061,24/MWh.

\section{DAFTAR PUSTAKA}

[1] J. Clerk Maxwell, A Treatise on Electricity and Magnetism, 3rd ed., vol. 2. Oxford: Clarendon, 1892, pp.68-73.

[2] I.S. Jacobs and C.P. Bean, "Fine particles, thin films and exchange anisotropy," in Magnetism, vol. III, G.T. Rado and H. Suhl, Eds. New York: Academic, 1963, pp. 271-350.

[3] K. Elissa, "Title of paper if known," unpublished.

[4] R. Nicole, "Title of paper with only first word capitalized," J. Name Stand. Abbrev., in press.

[5] Y. Yorozu, M. Hirano, K. Oka, and Y. Tagawa, "Electron spectroscopy studies on magneto-optical media and plastic substrate interface," IEEE Transl. J. Magn. Japan, vol. 2, pp. 740-741, August 1987 [Digests 9th Annual Conf. Magnetics Japan, p. 301, 1982]. 